\title{
THE SIGNIFICANCE OF HYPOGLYCAEMIA IN THE NEWBORN INFANT OF THE DIABETIC WOMAN
}

\author{
BY
}

\author{
JAMES W. FARQUHAR \\ From the Department of Child Life and Health, University of Edinburgh
}

(RECEIVED FOR PUBLICATION FEBRUARY 27, 1956)

The newborn infants of diabetic and of prediabetic women have morphological features which distinguish them from normal babies and which are of the greatest interest in the quest for further information about the aetiology of diabetes mellitus itself. In addition to these peculiarities of physical form, however, there are abnormalities of function during the first few days of life. Respiration may be established only with difficulty but it is more usual for the infant to start breathing normally. Progressive respiratory difficulty may appear shortly after birth and may assume a variety of forms such as unusually shallow breathing, choking due to the collection of mucus in the airway, or increasing embarrassment with laboured inspiration and costal indrawing. Other infants are subject to sudden attacks of respiratory arrest or slowing in which they become deeply cyanosed. These functional abnormalities are so diverse that they must differ in aetiology and they will be the subject of a later publication. In the literature, however, they are usually grouped together as 'cyanotic attacks' or 'colour changes' or 'respiratory incidents'. It is intended to use this terminology in the present paper, but in doing so the accuracy of the descriptive terms is not acknowledged. They have the virtue, however, of depicting a clinical picture to those who care for such infants.

The reduction of the foetal loss rate in pregnancy complicated by diabetes from a figure of over $40 \%$ less than a decade ago to around $15 \%$ in well controlled series today may be attributed to a combination of such factors as improved management of the diabetic state, stricter antenatal supervision, planned caesarean section with better anaesthesia and skilful supervision of the newly born child. Grave hazards are still met by the foetus both in utero and during the first few days after birth. There is also appreciable morbidity in the first week among the infants who ultimately survive.

The discovery that these infants commonly had remarkably low blood sugar levels led to the belief that the high morbidity and mortality might be due to hypoglycaemia. Alternatively a rapid and profound fall from a high intra-uterine level to a low normal neonatal level has been considered as being of aetiological significance. Although several investigations have been undertaken on this subject with particular reference to the neonatal mortality, some doubt still exists as to the clinical importance of hypoglycaemia and it was decided to attempt a final clarification.

Plan of the Investigation

Since 194890 infants born to proved diabetic women in the Simpson Memorial Maternity Pavilion, Edinburgh, have been studied personally. All have been observed continuously by experienced nurses and the nature of any abnormal incident has been recorded. Where these have lasted for longer than a minute or so they have been observed by an experienced paediatric house physician or by myself. All the abnormal incidents which persisted for 15 minutes or more have been observed personally and on repeated occasions the development and the course of the very brief incidents have been witnessed by myself.

In many of the earlier cases the blood sugar level was determined at regular intervals by a senior technician in the routine laboratory employing the method of Hagedorn-Jensen. Latterly the blood sugar level has been determined only if the course has been abnormal and only in the presence of symptoms. As only a proportion of the cases (about one third) was symptomatic and as a doctor was not always on the spot with the necessary apparatus when symptoms actually developed, the blood sugar level at the time of abnormal incidents is not available for each case. These blood sugar determinations form the preliminary part of the investigation and answer the first question, Do the incidents occur in association with hypoglycaemia? These findings must be considered also in relation to the second part of the study. 
Although personal doubt was expressed about the need to give glucose to these infants after birth, its intramuscular use was found safe and it was given until 1952. Before 1948 glucose was given intravenously but, following a short and highly unsatisfactory experience of oral administration, a change was made in that year to the intramuscular injection of $20 \%$ to $50 \%$ solutions. The fact that some infants received glucose in no way invalidates the use of this group. Since 1952 its use has been confined to a few test cases.

Serial blood sugar levels of two groups of newborn infants were studied. The first consisted of 32 babies who conformed to certain criteria of normality (Farquhar, 1954) and the second was composed of 17 infants born to diabetic women. The two groups were dissimilar also in that the normal infants were delivered spontaneously by the vagina at full term, whereas the abnormal infants were delivered by caesarean section about the thirty-sixth week for reasons which will be published elsewhere by Matthew. The intention of the study, however, was to discover just how abnormal the chemical behaviour of the infants of diabetic women was, irrespective of the method of delivery, and to find out if the clinical behaviour of the latter group could be correlated with an abnormal pattern of movement in the blood sugar. For this purpose such differences may be ignored.

Blood sugar levels were determined in duplicate in the infants of each group at birth, half hourly until 2 hours and then two hourly until 6 hours. The levels were not followed beyond this point in the first day as a small pilot study had shown that levels stabilized by about that time. Thereafter the blood sugar was determined daily at 6 a.m. after a fast of eight hours. The chemical method and its accuracy were exactly as described previously (Farquhar, 1954). The determinations were done personally. With the exception of Cases 59,69 and 70 (whose blood sugar pattern did not differ significantly from that of the group as a whole), none of these infants received glucose at birth and none of them was fed until day four or five. The exceptions received only $1 \mathrm{~g}$. of glucose by deep intramuscular injection at birth.

All live born infants who died in the newborn period were examined post mortem and the findings recorded. The pancreas was subjected to special examination in each case by Dr. R. F. Ogilvie.

\section{Results}

'Respiratory incidents' were observed in 34 of the 90 infants studied and the blood sugar level at the time of symptoms was determined in 23 of these. The results in 21 of the symptomatic cases are recorded in Table 1 along with an indication of the severity and of the duration of the clinical disturbance. It is clear that no correlation exists between severity and hypoglycaemia. The blood sugar level may be high or 'normal' or low during continuous mild or severe disturbances or at the time of brief upsets. The opportunity arose in 1954 of comparing the widely different clinical progress of dizygous twins neither of whom had been given glucose. These observations and the blood sugar

TABLE 1

SYMPTOMATIC CASES AND COINCIDENT BLOOD SUGAR LEVELS

\begin{tabular}{|c|c|c|c|c|}
\hline Case & Clinical Severity & $\begin{array}{l}\text { Time of } \\
\text { Incident }\end{array}$ & $\begin{array}{l}\text { Chemical } \\
\text { Method }\end{array}$ & $\begin{array}{c}\text { Blood Sugar Levels } \\
(\mathrm{mg} . \%)\end{array}$ \\
\hline $\begin{array}{r}1 \\
3 \\
6 \\
8 \\
14 \\
18\end{array}$ & $\begin{array}{l}\text { Delayed establishment of respiration } \\
\text { Continuous, moderate severe (inhalational) } \\
\text { Continuous, moderate severe (inhalational) } \\
\text { Continuous, mild } \\
\text { Continuous, severe (inhalational) } \\
\text { Continuous, moderate } \\
\quad \text { Fatal deterioration }\end{array}$ & $\begin{array}{l}\text { Birth } \\
\text { Birth to } 6 \mathrm{hr} \text {. } \\
\text { Birth to } 6 \mathrm{hr} \text {. } \\
\text { Birth to } 10 \mathrm{hr} \text {. } \\
4 \text { to } 6 \mathrm{hr} \text {. } \\
\text { Birth to } 8 \mathrm{hr} \text {. } \\
47 \text { to } 68 \mathrm{hr} \text {. }\end{array}$ & $\begin{array}{l}\text { H-J } \\
,, \\
, \\
, \\
,\end{array}$ & $\begin{array}{l}127 \\
66,50,70 \\
120,298,156 \\
60,78,74,74,64 \\
138,342 \\
254,180,180,86,52,114 \\
\text { Terminal level unk }\end{array}$ \\
\hline $\begin{array}{l}19 \\
35 \\
40\end{array}$ & $\begin{array}{l}\text { Continuous, severe initially with gradual } \\
\text { improvement } \\
\text { Continuous to death } \\
\text { Continuous, moderate } \\
\text { Sudden fatal deterioration }\end{array}$ & $\begin{array}{l}\text { Birth to } 24 \mathrm{hr} \text {. } \\
\text { Birth to } 2 \mathrm{hr} \text {. } \\
\text { Birth to } 3 \mathrm{hr} .50 \mathrm{~min} \text {. } \\
3 \mathrm{hr} \text {. } 50 \mathrm{~min} \text {. to } 4 \mathrm{hr} \text {. }\end{array}$ & $\begin{array}{l}\text { ", } \\
, "\end{array}$ & $\begin{array}{l}(522), 160,132,66,74,74,78,84,120,128 \\
\text { Terminal level } 71 \\
43,51,57 \text {. Terminal level } 62\end{array}$ \\
\hline $\begin{array}{l}41 \\
45 \\
46 \\
53 \\
69 \\
84 \\
85 \mathrm{a} \\
98 \\
100 \\
101 \\
102 \\
103\end{array}$ & $\begin{array}{l}\text { Delayed establishment of respiration } \\
\text { Continuous, mild } \\
\text { Continuous, moderate } \\
\text { Continuous, moderate } \\
\text { Continuous, severe } \\
\text { Rapid fatal deterioration } \\
\text { Twin. Acute, severe, short } \\
\text { Continuous to death } \\
\text { Acute, mild, short } \\
\text { Acute, mild, short } \\
\text { Continuous, severe } \\
\text { Acute, severe, short }\end{array}$ & $\begin{array}{l}\text { Birth } \\
\text { Birth to } 2 \mathrm{hr} \text {. } \\
\text { Birth to } 9 \mathrm{hr} \text {. } \\
3 \text { to } 6 \mathrm{hr} \text {. } \\
\text { Birth to Day } 4 \\
16 \mathrm{hr} \text {. } \\
\text { Day } 3 \\
3 \text { to } 41 \mathrm{hr} . \\
\text { Day } 6 \\
\text { Day } 3 \\
\text { Birth to } 4 \mathrm{hr} \text {. } \\
\text { Day } 4\end{array}$ & $\begin{array}{l}{ }^{\prime} \\
, \\
\dddot{\mathbf{R}} \\
\mathbf{R} \\
\mathbf{R} \\
\mathbf{H}-\mathbf{J} \\
\mathbf{H}-\mathbf{J} \\
\mathbf{H}-\mathbf{J} \\
\mathbf{H}-\mathbf{J} \\
\mathbf{H}-\mathbf{J}\end{array}$ & $\begin{array}{l}248 \\
55,52,46,63 \\
53,58,60,62,60 \\
56,60 \\
62,60,48,79,74,60,48,43 \\
265\left(\frac{1}{2} \text { hr. after } 1 \mathrm{~g} . \text { glucose intramuscularly) }\right. \\
111 \text { Terminal } 68 \\
41 . \text { Terming } \\
123 \\
94 \\
112,74 \\
43\end{array}$ \\
\hline
\end{tabular}

Ihe number of the case is that allocated to the pregnancy. As a number of these failed to result in the birth of a live child the case numbers exceed 100, although only 90 infants have been studied. 
levels are recorded in Table 2 and again there is no relationship between clinical behaviour and the sugar value.

TABLE 2

K. TWINS

\begin{tabular}{|c|c|c|c|c|}
\hline \multirow{2}{*}{ Time } & \multicolumn{2}{|c|}{ Twin 1 (Case 90a) } & \multicolumn{2}{|c|}{ Twin 2 (Case $90 b)$} \\
\hline & Condition & $\begin{array}{c}\text { Blood } \\
\text { Sugar } \\
\text { Level } \\
\text { (mg. \%) }\end{array}$ & Condition & $\begin{array}{c}\text { Blood } \\
\text { Sugar } \\
\text { Level } \\
(\mathrm{mg} . \%)\end{array}$ \\
\hline $2 \mathrm{hr}$. & $\begin{array}{l}\text { Good } \\
\text { Good }\end{array}$ & $\begin{array}{l}39 \\
44\end{array}$ & $\begin{array}{l}\text { Very poor } \\
\text { Slight } \\
\text { improvement }\end{array}$ & $\begin{array}{l}75 \\
58\end{array}$ \\
\hline $\begin{array}{l}14 \mathrm{hr} . \\
26 \mathrm{hr} .\end{array}$ & $\begin{array}{l}\text { Good } \\
\text { Good }\end{array}$ & $\overline{73}$ & $\begin{array}{l}\text { Poor } \\
\text { Impending } \\
\text { death }\end{array}$ & $\begin{array}{l}58 \\
67\end{array}$ \\
\hline
\end{tabular}

The result of the investigation into the serial blood sugar levels of normal babies has been published in detail (Farquhar, 1954). A wide range of values existed at any point after birth in the group as a whole and individuals showed variation from one time interval to another. These variations were greatest in the first six hours, and both the scatter of values in the group and the fluctuation of individuals within it became less marked as the infants grew older. This behaviour may be seen in Table 3 where the means of the duplicate readings have been taken to the nearest milligramme and provide sufficiently accurate data for the present study. No characteristic chemical behaviour existed and with the exception of Case 1 the blood sugar never fell below $40 \mathrm{mg}$. \%.

The results in the group of infants born to diabetic women have not been published previously and are given in Tables 4 and 5 . The scatter of values was again greater on the first than on other days and the
TABLE 3

INDIVIDUAL PATTERNS OF MOVEMENT OF THE BLOOD SUGAR (mg. \%) IN 32 NORMAL NEWBORN INFANTS

\begin{tabular}{|c|c|c|c|c|c|c|}
\hline \multirow{2}{*}{ Case } & \multirow{2}{*}{ Birth } & \multicolumn{5}{|c|}{ Hours } \\
\hline & & $\frac{1}{2}$ & 1 & 2 & 4 & 6 \\
\hline $\begin{array}{l}\mathbf{A} \\
\mathbf{B} \\
\mathbf{C} \\
\mathbf{D} \\
\mathbf{E} \\
\mathbf{F} \\
\mathbf{G} \\
\mathbf{H} \\
\mathbf{I} \\
\mathbf{J} \\
\mathbf{K} \\
\mathbf{L} \\
\mathbf{M} \\
\mathbf{N} \\
\mathbf{O} \\
\mathbf{P} \\
\mathbf{Q} \\
\mathbf{R} \\
\mathbf{S} \\
\mathbf{T} \\
\mathbf{U} \\
\mathbf{V} \\
\mathbf{W} \\
\mathbf{X} \\
\mathbf{Y} \\
\mathbf{Z} \\
\mathbf{a} \\
\mathbf{b} \\
\mathbf{c} \\
\mathbf{d} \\
\mathbf{e} \\
\mathbf{f}\end{array}$ & $\begin{array}{r}86 \\
82 \\
56 \\
71 \\
71 \\
55 \\
59 \\
77 \\
87 \\
69 \\
53 \\
71 \\
68 \\
95 \\
105 \\
102 \\
80 \\
88 \\
81 \\
81 \\
82 \\
66 \\
78 \\
90 \\
89 \\
85 \\
74 \\
61 \\
43 \\
65\end{array}$ & $\begin{array}{r}62 \\
72 \\
71 \\
59 \\
71 \\
82 \\
44 \\
69 \\
95 \\
84 \\
79 \\
53 \\
68 \\
69 \\
74 \\
98 \\
105 \\
71 \\
85 \\
61 \\
87 \\
96 \\
58 \\
83 \\
127 \\
75 \\
97 \\
57 \\
60 \\
48 \\
118\end{array}$ & $\begin{array}{r}66 \\
54 \\
57 \\
72 \\
60 \\
50 \\
80 \\
40 \\
105 \\
69 \\
102 \\
53 \\
61 \\
60 \\
63 \\
92 \\
111 \\
73 \\
83 \\
58 \\
76 \\
87 \\
52 \\
77 \\
121 \\
60 \\
83 \\
44 \\
49 \\
47 \\
97\end{array}$ & $\begin{array}{r}62 \\
43 \\
56 \\
62 \\
69 \\
49 \\
51 \\
70 \\
38 \\
68 \\
69 \\
85 \\
55 \\
64 \\
56 \\
61 \\
81 \\
79 \\
74 \\
75 \\
61 \\
70 \\
102 \\
45 \\
81 \\
72 \\
52 \\
61 \\
42 \\
65 \\
68 \\
77\end{array}$ & $\begin{array}{l}57 \\
50 \\
68 \\
70 \\
70 \\
51 \\
50 \\
58 \\
32 \\
56 \\
59 \\
72 \\
62 \\
61 \\
58 \\
64 \\
86 \\
68 \\
71 \\
72 \\
61 \\
57 \\
87 \\
56 \\
79 \\
66 \\
54 \\
74 \\
57 \\
67 \\
62 \\
76\end{array}$ & $\begin{array}{l}66 \\
65 \\
66 \\
69 \\
47 \\
45 \\
67 \\
39 \\
71 \\
61 \\
67 \\
72 \\
60 \\
42 \\
63 \\
86 \\
68 \\
72 \\
73 \\
57 \\
75 \\
90 \\
62 \\
68 \\
69 \\
51 \\
60 \\
58 \\
49 \\
62 \\
60\end{array}$ \\
\hline
\end{tabular}

range became less as the infants grew older. It is clear, however, that the pattern of movement was quite different from that in the normal group and that a characteristic fall in the blood sugar level occurred. The latter began at birth and it was maximum at one to two hours after delivery. In all these infants except Case 84 (who died at 16 hours) the blood sugar was rising again from four hours after birth and remained fairly stable thereafter.

TABLE 4

INDIVIDUAL PATTERNS OF MOVEMENT OF THE BLOOD SUGAR (mg. \%) IN 17 INFANTS BORN TO DIABETIC WOMEN FROM BIRTH TO 6 HOURS

\begin{tabular}{|c|c|c|c|c|c|c|}
\hline \multirow{2}{*}{ Case } & \multicolumn{6}{|c|}{ Hours } \\
\hline & B & $\frac{1}{2}$ & 1 & 2 & 4 & 6 \\
\hline $\begin{array}{l}70 \\
59 \\
60 \\
63 \\
64 \\
69 \\
65 \\
71 \\
72 \\
73 \\
74 \\
75 \\
83 \\
84 \\
85 a \\
85 b \\
88\end{array}$ & $\begin{array}{c}50,51 \\
56,55 \cdot 5 \\
51,51 \\
49 \cdot 5, \quad 50 \\
112,112 \\
61,63 \\
76,78 \\
91,92 \cdot 5 \\
52,53 \\
48,46 \cdot 5 \\
55 \cdot 5,57 \\
61 \\
72,72 \\
149,144 \\
63,61 \\
56,58 \\
52,50\end{array}$ & $\begin{array}{cc}23, & 25 \\
42, & 42 \cdot 5 \\
38 \cdot 5, & 39 \cdot 5 \\
23, & 23 \\
74, & 75 \\
59, & 61 \\
29, & 30 \\
43, & 43 \\
35 \cdot 5, & 35 \cdot 5 \\
34 \cdot 5, & 35 \\
26 \cdot 5, & 25 \cdot 5 \\
18, & 20 \\
57 & \\
97, & 96 \\
55, & 53 \cdot 5 \\
40, & 40 \\
68, & 68\end{array}$ & $\begin{array}{c}20 \cdot 5, \quad 21 \cdot 5 \\
35,35 \\
44 \cdot 5,44 \cdot 5 \\
17, \quad 18 \\
46,45 \cdot 5 \\
54 \cdot 5,53 \cdot 3 \\
21 \cdot 5, \quad 20 \\
27 \cdot 5, \quad 28 \\
29 \cdot 5,31 \\
39, \quad 38 \\
20 \cdot 5,19 \cdot 5 \\
14 \cdot 5, \quad 16 \\
42 \cdot 5,41 \\
62,60 \\
44 \cdot 5,44 \\
33, \quad 33 \\
65,66 \cdot 5\end{array}$ & $\begin{array}{c}17 \cdot 5,18 \cdot 5 \\
57,57 \cdot 5 \\
34,31 \\
23 \cdot 5,22 \cdot 5 \\
39 \cdot 5,38 \cdot 5 \\
48,48 \\
24 \cdot 5,25 \\
25,23 \\
37,37 \\
58 \cdot 5,58 \\
27 \cdot 5 \\
40,34 \cdot 5 \\
22, \quad 26 \\
21,21 \cdot 5 \\
48,48 \\
42,40 \cdot 5 \\
60,60\end{array}$ & $\begin{array}{cl}42, & 44 \\
86 \cdot 5, & 85 \cdot 5 \\
85, & 81 \\
33, & 31 \\
74, & 73 \\
78 \cdot 5, & 79 \cdot 5 \\
54 \cdot 5, & 52 \cdot 5 \\
36, & 37 \\
53, & 53 \\
76 \cdot 5, & 76 \cdot 5 \\
50, & 51 \cdot 5 \\
42, & 46 \cdot 5 \\
57 \cdot 5, & 59 \cdot 5 \\
21, & 21 \\
66, & 67 \\
72 \cdot 5, & 74 \\
52, & 52\end{array}$ & $\begin{array}{c}59,60 \\
70,69 \cdot 5 \\
91 \cdot 5,91 \\
39 \\
67,67 \\
74 \cdot 5,73 \\
66,65 \\
60 \cdot 5,58 \cdot 5 \\
53,53 \cdot 5 \\
66,66 \\
45 \cdot 5,45 \cdot 5 \\
42 \cdot 5,40 \cdot 5 \\
68,70 \cdot 5 \\
36,37 \cdot 5 \\
81,81 \cdot 5 \\
76,77 \cdot 5 \\
53 \cdot 5,51\end{array}$ \\
\hline $\begin{array}{l}\text { Mean } \\
\text { S.D. }\end{array}$ & $\begin{array}{l}68 \\
25 \cdot 6\end{array}$ & $\begin{array}{l}45 \cdot 13 \\
20 \cdot 3\end{array}$ & $\begin{array}{l}36 \cdot 24 \\
14 \cdot 8\end{array}$ & $\begin{array}{l}36 \cdot 53 \\
13 \cdot 4\end{array}$ & $\begin{array}{l}57 \cdot 78 \\
18 \cdot 4\end{array}$ & $\begin{array}{l}61 \cdot 63 \\
14 \cdot 9\end{array}$ \\
\hline
\end{tabular}


TABLE 5

INDIVIDUAL PATTERNS OF MOVEMENT OF THE BLOOD SUGAR (mg. \%) IN 16 INFANTS BORN TO DIABETIC WOMEN FROM SECOND TO TENTH DAYS

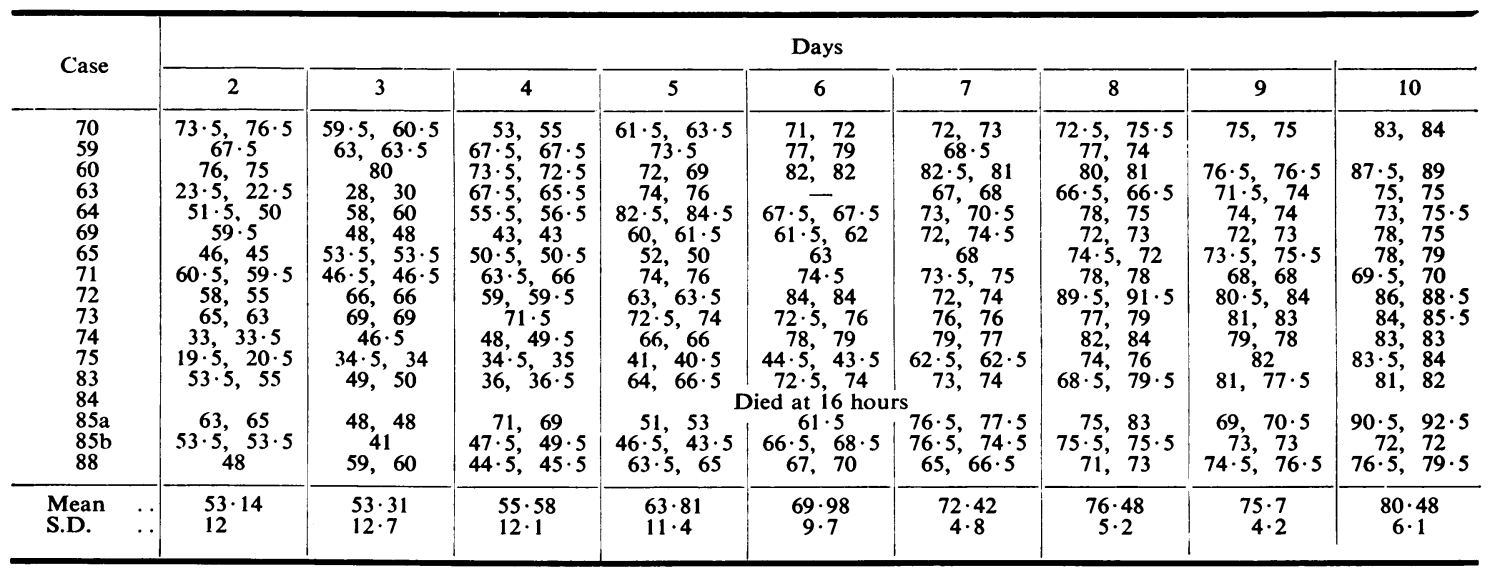

The difference in the behaviour of the two groups, taken as a whole, is fairly accurately reflected in the arithmetic means of the groups at each time interval (Fig. 1).

Having demonstrated the dissimilarity of these two groups and the fact that the blood sugar level of the infants born to diabetic women reached its lowest point at one to two hours after birth, it was then possible to examine the behaviour of such infants in the whole series for whom serial blood sugar values in the first few hours of life were available. The value at birth was plotted graphically against the lowest level at 1 to 3 hours and the point was marked with a symbol signifying the nature of the clinical course (Fig. 2). The segment of the circle is divided into three sections in the uppermost of which lie points which signify that a fall occurred in excess of $50 \%$ of the birth level. In the central section lie points where a fall occurred which was less than $50 \%$ of the birth level and in the lowest section lie the points where the blood sugar actually rose after birth (probably in response to administered glucose).

The deaths are fairly evenly spread, but there are only five for whom figures are available, and of these only three babies were abnormal in the first few hours. The two infants who were asymptomatic in the period of lowest blood sugar are located in the topmost section, whereas of the three who were symptomatic in the first few hours, two are in the
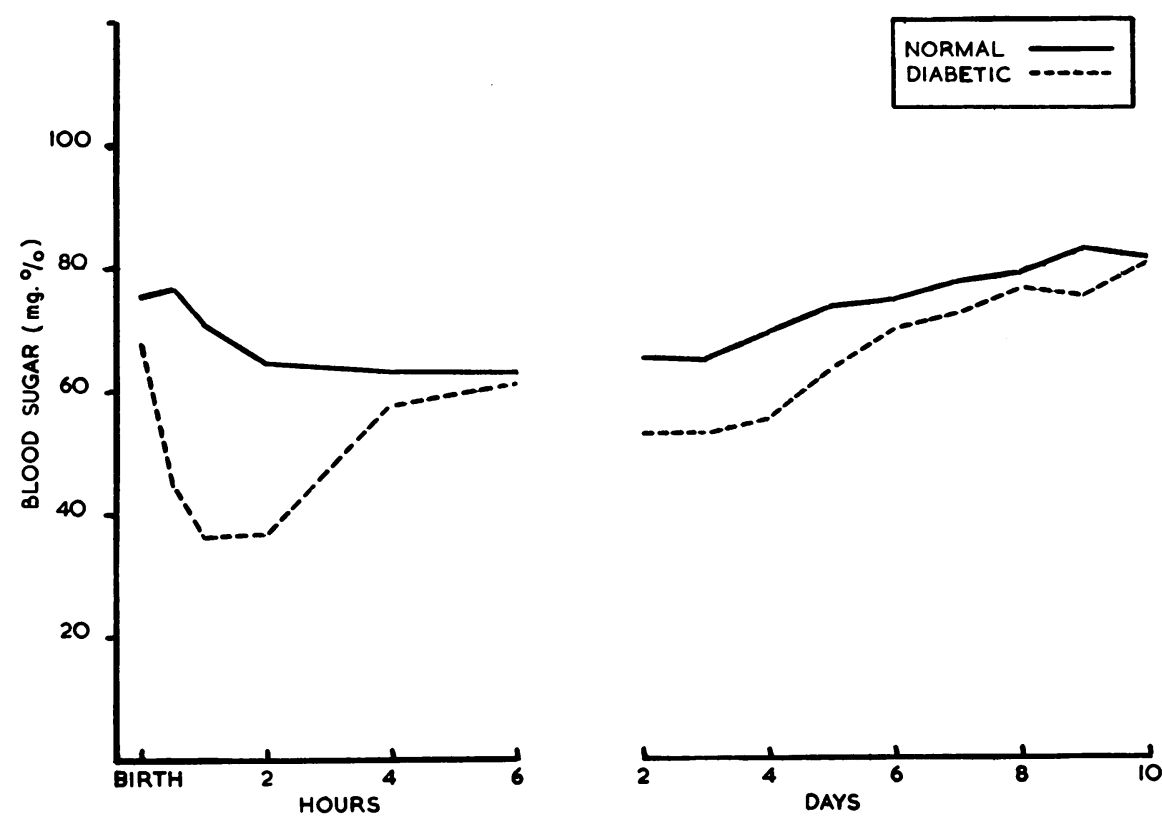

Fig. 1.-Arithmetic means of the blood sugar levels in a group of normal infants and in a group of infants of diabetic women. 
TABLE 6

NECROPSY FINDINGS IN NEONATAL DEATHS OF INFANTS OF DIABETIC WOMEN

\begin{tabular}{|c|c|}
\hline Case & Necropsy Findings \\
\hline 9 & \multirow{4}{*}{$\begin{array}{l}\text { Pneumonia } \\
\text { Terminal inhalation } \\
\text { Massive adrenal haemorrhage } \\
\text { Hyaline membrane } \\
\text { Intracranial haemorrhage } \\
\text { Prematurity }(1,644 \mathrm{~g} ., 30 \mathrm{wk} .) \\
\text { Asphyxia } \\
\text { Massive cerebral haemorrhage } \\
\text { Hyaline membrane } \\
\text { Atelectasis } \\
\text { Prematurity ( } 850 \mathrm{~g} ., 30 \mathrm{wk} .) \\
\text { Renal thrombosis }\end{array}$} \\
\hline $\begin{array}{l}18 \\
32 \\
35\end{array}$ & \\
\hline $\begin{array}{l}40 \\
84\end{array}$ & \\
\hline $\begin{array}{l}90 b \\
\text { Twin } 2 \\
98\end{array}$ & \\
\hline
\end{tabular}

centre of the middle section and one is in the lowest section.

Only 10 of the 54 infants represented on this graph were symptomatic in the first few hours when the trough of hypoglycaemia is normally attained. Three of the 10 died (Case 18 at 3 days, Case 32 at 11 hours and Case 40 at 4 hours) and none of them feature in the top section; two are in the middle section and there is one in the lowest. In two of the 10 symptomatic infants (Cases 3 and 6) the respiratory difficulties were undoubtedly the result of inhaling orally administered glucose. One other infant (Case 37) who is represented in the top section was apnoeic for some minutes after his initial cry, but he was perfectly normal at the time when his lowest blood sugar level was recorded. One (Case 69) had no significant fall in the blood sugar level (62 to $48 \mathrm{mg}$. \%) while another (Case 46) showed a rise from $53 \mathrm{mg}$. $\%$ to $62 \mathrm{mg}$. \%. One (Case 1) falls clearly into the topmost section and the last of the 10 (Case 19) also does so but the initial level of $522 \mathrm{mg} . \%$ certainly does not represent accurately the birth level of blood sugar as there were some minutes of delay in obtaining the specimen and the infant had been given $2 \mathrm{~g}$. of glucose into the umbilical vein on delivery. Of these 10 infants, therefore, who were symptomatic when the maximum fall in blood sugar was to be expected, only three fall into the topmost section and of these one was asymptomatic at the most hypoglycaemic point, while in another the sugar level at birth did not represent the true facts. There are 17 infants in the topmost section of the segment, so that at least 15 of these were asymptomatic at the time interval during which the blood sugar of these infants is normally at its lowest. The symptoms presented

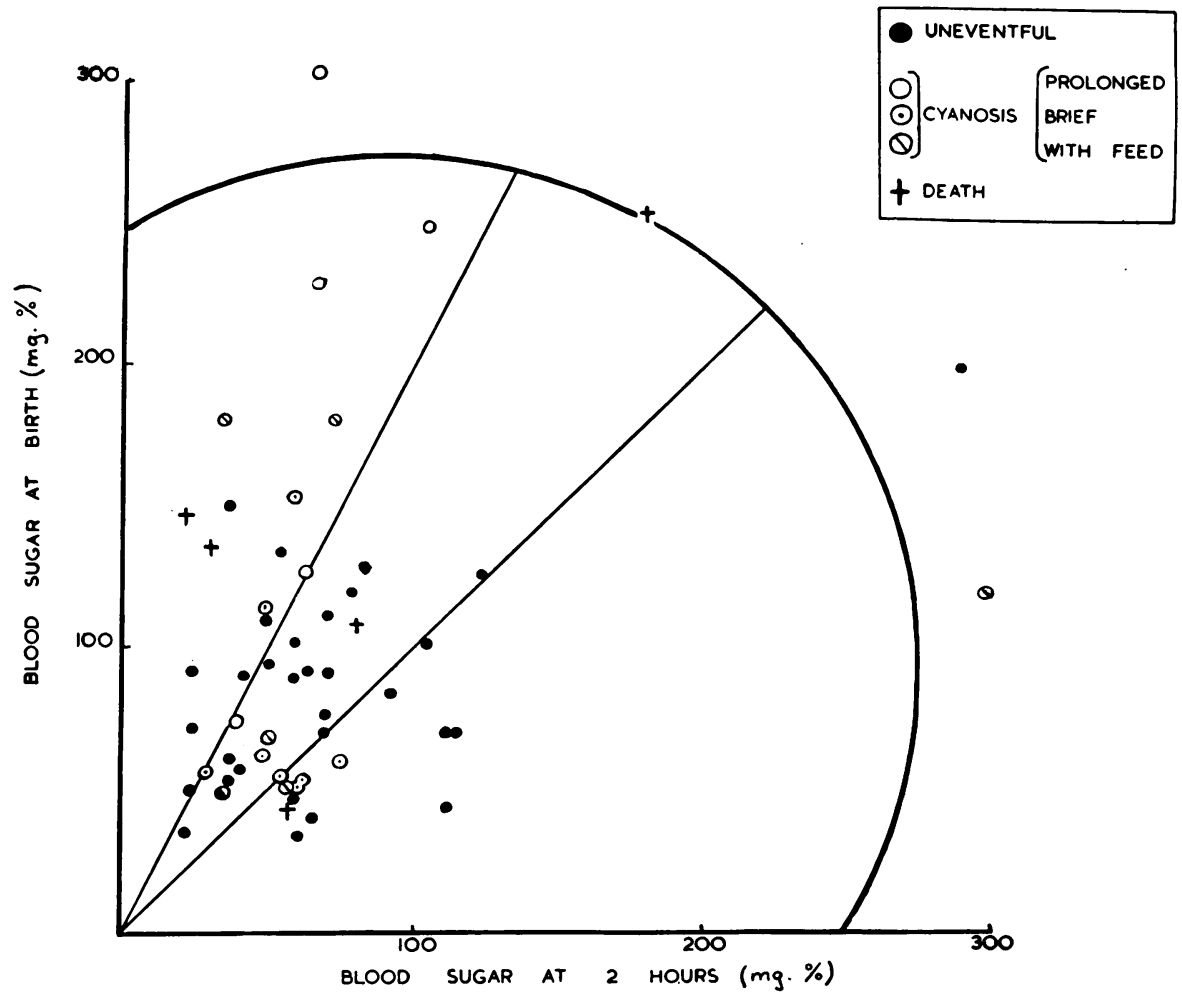

FIG. 2.-Relationship between blood sugar levels at birth and at 2 hours in infants of diabetic women. beyond the first few hours in the remaining 44 infants bear no relationship to the change on blood sugar immediately after birth and occurred at a time when the sugar level had become stabilized.

In the series of 90 live born infants there have been eight neonatal deaths. With one exception these have been among the lighter infants. Very adequate cause for death has been found in seven at necropsy and in the eighth (Case 40, whose blood sugar rose from birth) the clinical and patho- 
logical picture was of anoxia, although its cause was not determined. The important pathological findings are given in Table 5 and in addition the pancreas of each baby was found to have very definite hyperplasia of the islets of Langerhans. In Cases 18, $35,40,84,90 \mathrm{~b}$ and 98 , either serial blood sugar levels or one preceding death are available and in none was hypoglycaemia present. Case 9 was a preventable death from neonatal pneumonia on day 9, and Case 32 (whose blood sugar underwent a minimal fall) presented signs of respiratory embarrassment immediately after birth and went on to die of pulmonary hyaline membrane at 11 hours.

\section{Discussion}

Before 1937 sporadic reports concerning a few infants born to diabetic women showed that these babies had blood sugar levels soon after birth which were abnormally low when judged by adult standards. In that year the much more thorough investigation of Hartmann and Jaudon demonstrated the fact that the normal infants of nondiabetic women had lower sugar levels in the blood than the adult but that even more hypoglycaemic levels existed in the offspring of diabetics. Fuller studies of the blood sugar in the normal newborn followed, and Farquhar (1954) added a further group in which the levels were determined repeatedly in the first six hours and daily thereafter. The analyses were carrizd through in duplicate by a suitable method and the specimens which were taken after the first day always followed an eighthour fast, an omission which had cast some doubt on the value of previous investigations. From this and the preceding papers it was confirmed that the newly born infant might normally possess a low blood sugar level and that he might do so without showing any sign of clinical disturbance.

Miller and Ross (1940) carried out a small number of blood sugar determinations by the micro-method of Somogyi in the first $\mathbf{4 8}$ hours of life in premature and full-term infants of non-diabetics and in the infants of diabetic women. The last group had blood sugar levels similar to the prematures but significantly lower than the mature normals. It is not clear whether glucose was given to any of these infants or not. Reis, DeCosta and Allweiss (1950) compared the blood sugar levels of infants of normal women with those born to diabetic mothers. They employed the Somogyi modification of the ShafferHartman micro-method, but they did not state its accuracy in their hands or the length of fast before blood was withdrawn. They do not give individual figures for the infants but the 'diabetic group' as a whole shows lower levels than the normal in the first two hours. Beyond that period few of the abnormal group had the level determined. They state that "the blood sugar of babies born of diabetic mothers falls more rapidly during the first hour of life, falls lower, and returns to normal more slowly'. Komrower (1954) used a modified Folin and Wu micro-method in his study of normal infants and those of diabetic women. Duplicate determinations were made 'as often as possible', but the accuracy in his hands was not stated. The groups were studied in the important first 24 hours of life but not beyond this. Again it was shown that the infants of diabetics 'revealed a rapid drop in the first hours of life with a slow rise towards the end of the first 24 hours'. Pedersen (1952), and Pedersen, Bojsen-Møller and Poulsen (1954), on the other hand, who have carried out a great deal of very careful work on the subject of the diabetic pregnancy, employed the Hagedorn-Jensen method (the determinations were done by 'two experienced technicians' for the most part), but do not appear to have examined duplicate specimens. The accuracy of the method was repeatedly checked against glucose standards and 'the maximum deviation from the true value did not exceed $5 \%$ '. His figures are at variance with the others quoted for he was unable to demonstrate any difference in the blood sugar patterns of the normal and abnormal groups. The present study, however, shows that there is indeed a more profound and more rapid fall in the blood sugar levels of the infants of diabetic women, but that this is corrected spontaneously by six hours after delivery. By the second day the diabetic group again shows significantly low sugar values, but this gap is narrowed and becomes insignificant when feeding of the abnormal group gets under way on days five or six.

With the important exception of the results of Pedersen et al., therefore, it appears to be agreed that these infants show a profound drop in the first few hours. There is less agreement about when stabilization occurs, but the experience of this study has shown fairly consistent correction by six hours. Earquhar (1954) has reviewed the theories about control of the blood sugar level in the neonatal period. Although some authors have sought to incriminate hepatic immaturity in the aetiology of neonatal hypoglycaemia there is little to suggest it. On the other hand, the neonatal adrenal cortex is undergoing remarkable involution in the first week and, in the infant of the diabetic, the pancreatic islets are usually hyperplastic. The latter observation was made first by Dubreuil and Anderodias (1920) and more than 20 papers followed it, including the excellent study of the morphology of infants of 
diabetic pregnancies by Cardell (1953). It seems likely that there is an absolute increase in islet tissue in these infants and it has been the general opinion that this is due to an increase in the beta cells. If indeed there is an abnormally high output of insulin in these infants then a rapid fall in the blood sugar level immediately following birth would be expected. White (1949) was opposed to the theory of an absolute hyperinsulinism on the basis that the blood sugar level should then fall to zero, but this would be the case only if the pancreas continued to secrete insulin in the presence of hypoglycaemia and if there were no opposing mechanism such as the adrenal cortex. Pedersen (1952) and Pedersen et al. (1954) believed that the blood sugar level in the mother dictated the foetal liver threshold for glucose by determining the foetal output of insulin. Thus hyperglycaemia in the mother would stimulate foetal insulin production and the hepatic threshold would be low so that the blood sugar level in the infant would fall from a high birth level to the low liver threshold level after birth. This would mean that lower maternal levels would result in higher levels in the newborn and so the fall after birth would not be excessive. This is the explanation offered by Pedersen to explain why his group of abnormal infants did not differ in its blood sugar pattern from the normal group. Every effort was made to keep the mother's blood sugar within normal limits. Careful diabetic control was maintained in the women of this series by Dr. C. F. Rolland and yet the blood sugar of the infants fell profoundly and quickly. The spontaneous rebound in this study to a figure approaching the birth value indicates the presence of an adequately functioning mechanism opposing insulin. The facts would appear to be compatible with a state of increased insulin production which rapidly reverts to normal when the stimulus to production is withdrawn and/or when it is opposed by diabetogenic hormones from the adrenal cortex, chromaffin tissue or the pancreas itself.

- It is clear, therefore, that the infants of diabetic women may have very low blood sugar levels in the hours after birth and also that they may have a variety of symptoms which may be classified roughly as respiratory, but it remains to be shown whether or not any relationship exists between these two findings.

Hartmann and Jaudon (1937) were of the opinion that cyanosis, irritability, listlessness, hypotonicity, hypertonicity, twitchings and even death might result from hypoglycaemia. They stated 'there can be no question, however, of the greater tendency in the abnormal (diabetic) group to develop extreme grades of hypoglycaemia with clinical manifestations severe enough to be fatal or so alarming as to require constant watching and sometimes frequent treatment to raise low blood sugar levels'. Miller and Ross (1940) noted symptoms in three of six infants and although the infants were biochemically hypoglycaemic they noted other abnormalities in the babies; congestive failure in two and possible birth injury or erythroblastosis foetalis in another. They noted a lag in the response of the infants to glucose, but felt this was analogous to the delayed response of a hypoglycaemic non-diabetic adult to glucose. Reis et al. (1950) enumerated the dangers to which these newborn infants were exposed and included hypoglycaemia without giving their reasons. John (1950) stated that the physiological hypoglycaemia of healthy newborn infants was benign and unproductive of symptoms, but that the hypoglycaemia which the offspring of diabetic women developed was malignant, leading to shock and to death unless it were treated early and energetically. Komrower (1954) in a comprehensive study observed signs which were considered to be suggestive of hypoglycaemia in four of $\mathbf{4 0}$ such infants whose blood sugar levels had been followed carefully from birth. In three the levels were less than $20 \mathrm{mg}$. \% and the fourth baby had been subjected to a large and very rapid drop in blood sugar. On the other hand, Komrower found three infants who were symptom free with sugar levels of $20 \mathrm{mg}$. \% or less. There is, however, some individual variation in the response of adults to hypoglycaemia and the epileptic in particular may respond with convulsions to a blood sugar level which would be responsible for milder symptoms only in a normal person. All of the deaths in Komrower's series appeared to be explicable on the basis of the pathological findings, without his requiring to incriminate hypoglycaemia. In 11 of 27 infants born to diabetic and prediabetic women, Reardon, Field and Baumann (1955) determined the blood sugar value at 4 hours. Seven of these had values of less than $15 \mathrm{mg}$. \% and four of them died. Referring to the low blood sugar levels attained by normal infants of non-diabetic women, Donald (1956) stated 'the sharp change may well tax the child's endurance and metabolic resources overwhelmingly'. Pedersen (1952), whose work is the exception to the finding that infants of diabetic women have a more profound and more rapid fall in blood sugar, discovered no clinical evidence of hypoglycaemia in his group. Such abnormalities as did present in the first 24 hours of life were attributed to intracranial haemorrhage in one (diagnosed by cranial puncture), congenital heart disease in one (diagnosed by auscultation and 
radiography), widespread atelectasis in two (diagnosed by auscultation and necropsy in one and by auscultation and radiography in another) and probable atelectasis in the fifth in which the diagnosis could not be verified. He did not note the blood sugar to be abnormal in the presence of cyanosis in these babies.

Those obstetricians and paediatricians who have feared the effects of hypoglycaemia upon the infants of diabetics have suspected that, although such low levels may not be productive of symptoms at the exact moment when the trough of hypoglycaemia was reached, nevertheless the structure and the function of, for example, the brain, the heart, the lungs, or the vessels might have been so altered by it that symptoms might develop later, even after the blood sugar had been somewhat restored. These are very hypothetical considerations, but they are possible and they must receive an answer.

It is believed that this study has confirmed that the blood sugar falls further and more rapidly in the infants of diabetic women than in those of normal women. It has also been shown that the infants in the 'diabetic' group may have blood sugar levels which may be described as low or normal or high in the presence of 'respiratory' incidents and that there is no relationship between these incidents and the blood sugar level at that time. It has also been shown that there is no relationship between the magnitude and speed of the fall in blood sugar and the development of abnormal signs in the babies. Finally it is believed that it has been shown that there is no relationship between the magnitude and/or the speed of the fall in blood sugar and the development of abnormal incidents later in the first two weeks of life.

Following the completion of this investigation an attempt has been made to examine all the surviving children as a logical sequel to the previous work in order to exclude the possibility of hypoglycaemia having caused cerebral damage which had passed unrecognized at the time. Of the 90 infants born, 82 survived the newborn period. One of these (Case 30) died suddenly at home at the age of 1 month. His neonatal course in hospital was quite uneventful. The blood sugar fell from a birth level of $94 \mathrm{mg} . \%$ to $72 \mathrm{mg} . \%$ at 1 hour and $50 \mathrm{mg} . \%$ at 3 hours from which point it rose steadily. Death was sudden and was associated with aspiration of a feed. His doctor heard a cardiac murmur for the first time just before the baby died and on this evidence alone certified death as having been due to congenital disease of the heart. There was no necropsy. Another infant (Case 3), whose neonatal course was complicated by inhalational incidents, but whose blood sugar was never abnormal, developed very severe meningococcal meningitis complicated by cerebral venous thrombosis at 2 months and suffers from secondary amentia.

Of the remaining 80 , all but five (three of whom have emigrated) have been traced and their present health assessed. Of the 75 children I have examined 69 personally; three have been examined for me by other physicians; the mothers have supplied detailed information by correspondence in two cases (one in the north of Scotland and one in Aden) and information was supplied about the remaining case by a children's officer.

From these various sources it can be said that 71 of the children are apparently normal in intelligence and behaviour. One (Case 42) has been in hospital since 1953 when at 3 years of age she developed Perthe's disease of the hip. The physician thought that at 5 years of age the child was a little backward, but it has not been possible to see her personally to assess how much of her retardation may be attributed to prolonged institutional care. The infant certainly had a normal neonatal course and was not hypoglycaemic at any point. Two children are certainly mentally defective, one being a mongol and the other is the surviving dizygous twin (Case 90a). The latter infant weighed only $1,021 \mathrm{~g}$. at birth, and although he had a rather low blood sugar level initially, it rose spontaneously and he was in good condition in the newborn period. He also suffers from retrolental fibroplasia.

Finally, Case 63 is a small boy who is undoubtedly dull, but whose home background is very bad. The mother was a prostitute, she was very unstable emotionally and she did not care for her children. She died while attempting to induce the miscarriage of a further pregnancy when the patient was only a few months old. The father, who is an unstable and violent man and whose intelligence may be subnormal, married again, but with no advantage to the family. The child has grown up unloved, without proper care and is backward and dirty at the age of $2 \frac{1}{2}$ years. Although his blood sugar level did in fact fall by over $50 \%$ in the first hour of life, and although it remained below $30 \mathrm{mg}$. \% on days two and three, he was quite asymptomatic throughout the neonatal period. Case 75, whose blood sugar fell by more than $75 \%$ in the first hour, and in whom it was $20 \mathrm{mg}$. \% on day two, and in whom the level did not exceed $40 \mathrm{mg}$. \% until day five, is at the same age a very normal little girl. It seems much more likely that the backwardness in Cases 90a and 63 is the result of factors other than the hypoglycaemia.

Hartmann and Jaudon (1937) recommended that 
the hypoglycaemia of these babies should be prevented by the very early institution of regular carbohydrate and milk feeds and that where symptoms developed the babies should have epinephrine and dextrose parenterally. Reis et al. (1950) recommended that a $50 \%$ glucose solution should be given orally by medicine dropper in the first hour of life and that after the first two hours the infant should receive $\frac{1}{2}$ to $1 \mathrm{oz}$. feeds two hourly of breast milk, and $5 \%$ glucose alternately during the first day of life. Whitely, Adams and Parrott (1953) recommended the subcutaneous administration of glucose to the newly born infant. Drury (1953) also recommended its parenteral administration. Komrower (1954) studied two groups one of which received no glucose, whereas the infants of the other received $2 \mathrm{~g}$. glucose by mouth as a $50 \%$ solution in the first eight hours of life. There was no significant difference in the blood sugar levels of the two groups, and Komrower, therefore, decided to give glucose only when symptoms attributable to hypoglycaemia developed. Pedersen $(1952,1954)$ saw no point in using glucose at all. The results of this investigation make it clear that there is no need to use glucose in the infants of diabetic women. Its oral administration is accompanied by a very real risk of vomiting and inhalation, while the parenteral administration of isotonic solutions subcutaneously or intravenously only serve to increase the abnormal volume of the body water. The intravenous use of hypertonic solutions may embarrass the heart by increasing the intravascular fluid volume. From 1948 to 1951 we used $20 \%$ to $50 \%$ solutions intramuscularly without complication. The present policy is in line with that of Pedersen (1952; Pedersen et al., 1954) and it is felt that not only is the use of glucose unnecessary, but it may hinder the establishment of the correct diagnosis by its suggesting that hypoglycaemia is the responsible factor.

Finally the investigation provides support for the policy adopted fully in Edinburgh by 1952 that all fluid should be withheld until the fourth or fifth day of life.
Summary

Confirmatory evidence is offered that the blood sugar level falls more profoundly and more rapidly in the infant of the diabetic mother than in the offspring of the normal woman. It is shown that there is no relationship between the development of a morbid neonatal course and the blood sugar level at the time or the extent and rapidity of the fall. It is shown also that there is no relationship between the degree of hypoglycaemia or the gradient of the change in levels and abnormal incidents later in the first two weeks of life. It is probable that there is no relationship between the blood sugar changes and subnormal intelligence in later childhood.

The administration of glucose may be dangerous and at the least it may serve to postpone the establishment of the correct diagnosis in abnormal infants.

I wish to express my gratitude to Professor R. W. B. Ellis for his encouragement and advice, the nursing staff of the Simpson Memorial Maternity Pavilion for their cooperation, Miss D. Trench of the Royal Edinburgh Hospital for Sick Children and the children's departments of various local authorities for extensive assistance in tracing the present whereabouts of the children and their parents, who have been generous in their help.

Part of this work was carried out during the tenure of the George Guthrie Research Fellowship in Child Health of this University.

REFERENCES

Cardell, B. S. (1953). J. Obstet. Gynaec. Brit. Emp., 60, 834

Donald, I. (1956). In Child Health and Development, ed. R. W. B. Ellis, 2nd ed, p. 26. London.

Drury, M. I. (1953). J. Irish med. Ass., 33, 91.

Dubreuil, G. and Anderodias, J. (1920). C. R. Soc. Biol. (Paris), 83, 1490

Farquhar, J. W. (1954). Archives of Disease in Childhood, 29, 519.

Hartmann, A. F. and Jaudon, J. C. (1937). J. Pediat., 11, 1.

John, H. J. (1950). Zbl. Gynäk., 72, 1766.

Komrower, G. M. (1954). Archives of Disease in Childhood, 29, 28.

Komrower, G. M. (1954). Archives of Disease in Childhor,

Miller, H. C. and Ross, R. A. (1940). J. Pediat., 16, 473. Newborn Infants during Fasting and Glucose Administration. Copenhagen.

Bojsen-Meller, B. and Poulsen, H. (1954). Acta endocr. (Kbh.) $15,33$.

Reardon, H. S., Field, S. H. and Baumann, B. S. (1955). Combined Meeting of the American Pediatric Society, British Paediatric Association, The Society for Pediatric Research, and Canadian Paediatric Society. Quebec. p. 188.

Reis, R. A., DeCosta, E. J. and Allweiss, M. D. (1950). Amer. J. Obstet. Gynec., 60, 1023.

White, P. (1949). Amer. J. Med., 7, 609.

Whitely, J. M., Adams, T. W. and Parrott, M. H. (1953). West. J. Surg., 61, 439. 